\title{
CONDIÇÕES ERGONÔMICAS DO TRABALHO DA EQUIPE DE ENFERMAGEM EM UNIDADE DE INTERNAÇÃO DE CARDIOLOGIA*
}

\author{
Maria Helena Palucci Marziale** \\ Emília Campos de Carvalho**
}

MARZIALE, M.H.P.; CARVALHO, E.C.de. Condições ergonômicas do trabalho da equipe de enfermagem em unidade de internação de cardiologia. Rev.latino-am.enfermagem, Ribeirão Preto, v. 6, n. 1, p. 99-117, janeiro 1998.

Com o objetivo de analisar as condições ergonômicas da situação de trabalho do pessoal de enfermagem em uma unidade de internação hospitalar, utilizamos como pressuposto metodológico a globalidade da situação experienciada através da análise de seus elementos quais sejam: o homem (trabalhador de enfermagem), a atividade de trabalho (tarefas prescritas, atividades reais e postos de trabalho) e o ambiente (temperatura, ruido e iluminação). Buscando a demanda para a investigação identificamos a unidade de Cardiologia como local para realização da pesquisa. Os resultados apontaram que as condições de trabalho na unidade estudada são insatisfatórias e que o trabalhador enfrenta problemas relacionados a inadequação de: salário, postos de trabalho, relacionamento, organização de trabalho, formação e atividades executadas. Diante da situação experenciada sugerimos algumas recomendações.

UNITERMOS: trabalho, enfermagem, ergonomia

\section{INTRODUÇÃO}

A preocupação com as condições de trabalho da enfermagem em hospitais vem atraindo a atenção de muitos pesquisadores, devido aos riscos que o ambiente oferece e aos aspectos penosos das atividades peculiares à assistência de enfermagem entre os quais destacam-se o desrespeito aos rítmos biológicos e aos horários de alimentação, falta de programa de trabalho, longas distâncias percorridas durante a jornada de trabalho, dimensão inadequada de mobiliários e a inexistência, insuficiência ou inadaptação de materiais.

No Brasil, o hospital é considerado uma instituição integrada ao setor terciário da economia, que apresenta grau de risco três, devido às operações insalubres ali realizadas e à presença de agentes biológicos responsáveis pelas infecções causadas por vírus, fungos e bactéria.

O ambiente hospitalar apresenta também, uma série de outros riscos decorrentes de fatores físicos, químicos, psicossociais e ergonômicos, os quais podem ser prejudiciais à saúde dos trabalhadores e por isso, devem ser analisados para que se possa caracterizar as condições de trabalho em cada instituição.

As condições de trabalho e os riscos ocupacionais podem ser analisados através de diferentes abordagens, dentre elas a ergonômica, a qual elegemos para ser utilizada nesta pesquisa.

Para a ergonomia, as condições de trabalho são representadas por um conjunto de fatores interdependentes, que atuam direta ou indiretamente na qualidade de vida das pessoas e nos resultados do próprio trabalho e que o homem, a atividade e o ambiente de trabalho são os elementos componentes da situação de trabalho.

\section{- O homem}

O homem ou trabalhador apresenta diferenças individuais tais como estatura, peso, compleição física, resistência à fadiga, capacidade auditiva e visual, memória, habilidade motora, personalidade que devem ser consideradas por atingir diferenças significativas (IIDA, 1990).

Além das características individuais as diferenças de formação profissional também leva o trabalhador a enfrentar de forma diferente seu trabalho. Segundo SANTOS et al.(1991) a formação profissional leva o indivíduo a enfrentar a situação de trabalho de maneira diferente, pois a especialidade ajuda a reduzir a carga mental e diminui a possibilidade de erro.

Centrando nossa atenção ao trabalhador de

* Artigo extraído da tese de doutorado apresentada ao Programa de Pós-Graduação - Enfermagem Fundamental da Escola de Enfermagem de Ribeirão Preto da Universidade de São Paulo

** Docentes da Escola de Enfermagem de Ribeirão Preto da Universidade de São Paulo 
enfermagem, observamos que legalmente as atividades de enfermagem devem ser realizadas por profissionais com diferentes níveis de formação: enfermeiros, formados em cursos de graduação de nível superior; técnicos de enfermagem, formados em cursos de segundo grau; auxiliares de enfermagem, formados em cursos de primeiro e segundo grau e atendentes de enfermagem, sem preparo formal, submetidos ou não a programas de treinamento (BRASIL, 1985). Sendo assim, o trabalhador possui uma divisão de trabalho hierarquizada, existindo atribuições de atividades de acordo com a categoria profissional estabelecidas pelo Conselho Federal de Enfermagem.

\section{- A atividade de trabalho}

A atividade de trabalho é composta pela tarefa prescrita (formal), pela tarefa real (efetivamente realizada), pelos instrumentos utilizados para realização da tarefa e pelo posto de trabalho (onde a tarefa é realizada).

A atividade de trabalho significa o trabalho real, efetivamente realizado pelo indivíduo, a forma pela qual ele consegue desempenhar suas tarefas. É resultado das definições impostas pela empresa com relação à sua tarefa e das características pessoais, experiência e treinamento do trabalhador (ABRAHÃO, 1993).

\section{- O ambiente}

O ambiente de trabalho é o local onde é executada a atividade de trabalho. São considerados como fatores componentes do ambiente de trabalho os dispositivos legais, regulamentos, considerações éticas, ruído, iluminação e a temperatura (SLUCHAK, 1992).

A análise das condições ergonômicas de trabalho deve conter além dos componentes anteriormente descritos, informações sobre os componentes secundários à situação de trabalho tais como: os meios de transporte, a alimentação e moradia, por serem imprescindíveis a saúde dos trabalhadores.

Em essência, as diretrizes seguidas nas pesquisas sob a ótica da ergonomia, segundo SLUCHAK (1992) são: determinar os problemas relacionados com a ergonomia nos locais de trabalho; identificar a natureza e localização desses problemas e implementar medidas para reduzir ou eliminá-los.

De maneira geral, a ergonomia é apresentada através das modalidades: de concepção que está relacionada ao estudo ergonômico de instrumentos e ambiente de trabalho antes de sua construção, de correção que procura melhorar as condições de trabalho já existentes e a de conscientização que se preocupa em conscientizar os trabalhadores através de treinamento, reciclagens para trabalharem de forma segura reconhecendo os fatores de riscos que podem surgir a qualquer momento no ambiente de trabalho (IIDA, 1990).

Diante das constatações efetuadas através da revisão da literatura, em relação à inadequação das condições de trabalho do pessoal de enfermagem nas instituições hospitalares, de nossa experiência profissional no ambiente hospitalar, da necessidade legal do estabelecimento de parâmetros que permitam a adequação das condições de trabalho às características psicofisiológicas dos trabalhadores e da adequação dos princípios da Ergonomia para abordar a referida temática, propusemo-nos a realizar esta investigação, com objetivo de:

- Analisar as condições ergonômicas da situação de trabalho do pessoal de enfermagem em uma unidade de internação hospitalar.

\section{MATERIAL E MÉTODO}

O pressuposto metodológico utilizado nesta investigação fundamenta-se nos princípios oriundos da ergonomia descritos por IIDA (1990); GUÉRIN et al. (1991) e SLUCHACK (1992) e buscam a globalidade da situação de trabalho através de três fases.

\section{Primeira fase: Determinação de problemas relacionados à ergonomia no local de trabalho}

Encaminhamos, a um hospital filantrópico de uma cidade do interior do Estado de São Paulo um ofício solicitando permissão para executarmos a pesquisa. Uma vez obtida a permissão, realizamos uma entrevista com a gerente do serviço de enfermagem.

Para coleta dos dados utilizamos a técnica de entrevista com o uso de roteiro semi-estruturado e registro gravado. $\mathrm{O}$ roteiro foi submetido a validação prévia no que se refere ao conteúdo, clareza e objetividade. Através dos resultados obtidos foi possível fazer um prédiagnóstico da situação.

O hospital estudado é uma instituição filantrópica que presta assistência geral a nível ambulatorial e de internação contando com 280 leitos. O serviço conta com 390 trabalhadores voltados à prestação da assistência, sendo $7,2 \%$ enfermeiros; $14,1 \%$ técnicos de enfermagem, $33,8 \%$ auxiliares de enfermagem e $44,9 \%$ atendentes de enfermagem.

\section{A seleção da unidade de internação a ser analisada}

A demanda para a realização da análise 
ergonômica foi eleita diante do problema de absenteísmo enfrentado no serviço de enfermagem, pois a ausência no trabalho pode ser considerada como indicador de inadaptação do trabalhador ao trabalho.

A seleção foi efetuada através do levantamento do índice de absenteismo-doença entre o pessoal de enfermagem alocado nas unidades de internação do hospital, através do cálculo de Índice de freqüência (If) e porcentagem de Tempo perdido (Tp) acumulados.(COUTO,1987). Segundo o referido autor If maiores que 0,10 por mês é considerado elevado e a situação de trabalho precisa ser avaliada.

Através de consulta ao livro de registro de licenças-saúde do ambulatório de atendimento aos trabalhadores do hospital, realizamos um levantamento retrospectivo da ocorrência de licenças-saúde ocorridas durante o ano de 1993. Através dos cálculos de Índice de freqüência (If) e da porcentagem de Tempo perdido (Tp) acumulados, foi possível selecionar a unidade de internação de Cardiologia para realização desta investigação uma vez que, Tp=5,5\% e If $=0,29$.

$\mathrm{Na}$ unidade de Cardiologia foram registrados 65 afastamentos por doença causando perda de 174 dias de trabalho, fato considerado prejudicial por estar comprometendo a força de trabalho e influenciando negativamente na qualidade de assistência de enfermagem prestada ao paciente.

Em relação aos problemas de saúde causadores das licenças saúde estes foram relativos a afecções no; sistema osteomuscular (24\%), sistema digestivo (21\%), sistema respiratório (18\%), aparelho reprodutor feminino (18\%), sistema circulatório ( $9 \%)$, sistema nervoso e órgão dos sentidos $(6 \%)$, sistema geniturinário(3\%) e a sinais e sintomas de afecções mal definidas (1\%). Muitos desses problemas certamente estão associados as condições do trabalho, devido a inadequação dos instrumentos e mobiliário utilizados, a organização do trabalho, as atividades executadas e a fatores do próprio ambiente.

Segunda fase: Identificação e localização de problemas relacionados aos componentes da situação de trabalho na unidade de internação de Cardiologia

\section{Procedimento}

Foram entrevistados os 22 funcionários lotados na unidade através de um roteiro contendo informações sobre dados biográficos, condições de trabalho, saúde e os dados antropométricos ( peso, altura e altura a nível do cotovelo).

Buscando a identificação de problemas relacionados ao componente atividade de trabalho utilizamos os procedimentos e instrumentos abaixo descritos.

\section{- Observação livre do trabalho na unidade}

Realizamos observações diretas das rotinas e do ambiente de trabalho da unidade durante os turnos da manhã, tarde e noite, perfazendo 24 horas de observação.

\section{- Consulta à documentos}

Realizamos consulta, ao Regimento técnico do serviço de enfermagem e da unidade de internação, afim de identificarmos as tarefas prescritas para os trabalhadores.

\section{- Observação direta sistemática da atividade de trabalho}

Buscando a identificação das atividades efetivamente realizadas, através da técnica de observação intermitente, os técnicos, auxiliares e atendentes de enfermagem, foram observados durante 600 minutos em cada um dos turnos (manhã, tarde e noite). Utilizamos a estratégia de observação intervalar, sendo que a cada uma hora de observação havia uma pausa de quinze minutos, uma vez que longos períodos de observação são considerados desaconselháveis, devido à dificuldade de percepção de detalhes.

Devido ao esquema de trabalho adotado, os enfermeiros ficam responsáveis por várias unidades, assim a observação de suas atividades foi realizada durante todas as vezes que os mesmos atuaram na unidade de Cardiologia durante os plantões destinados a coleta de dados, ou seja, durante os 600 minutos destinados à observação da referida categoria.

\section{- Observação direta sistemática dos postos de trabalho}

Através da utilização da técnica de observação direta, efetuamos a coleta de dados referentes aos espaços, dimensionamento dos mobiliários e superfícies e posturas corporais adotadas pelos trabalhadores ao realizarem algumas atividades junto ao posto de enfermagem e enfermarias.

Com vistas a averiguar a adequação dos postos em relação às posturas corporais adotadas, utilizamos o registro através de desenhos referentes à posição do dorso e das pernas. Para verificação do tempo de permanência em cada postura corporal e do tempo gasto para execução da atividade utilizamos um cronômetro e para aferição das dimensões dos espaços, superfícies e mobiliários utilizamos uma trena.

Para análise do ambiente de trabalho utilizamos os procedimentos e instrumentos abaixo descritos.

\section{- Observação do ambiente de trabalho e aferição de agentes físicos}

Através do método de observação direta 
sistematizada analisamos aspectos do ambiente de trabalho e efetuamos a aferição dos agentes físicos: temperatura, iluminação e ruído. A temperatura foi aferida em duas enfermarias e nos dois postos de enfermagem com utilização de um conjunto de termômetros de globo, bulbo úmido e bulbo seco. A iluminação foi aferida pelo uso de luxímetro digital LD-500 ICEL e os níveis de ruído através da utilização de um decibelímetro ETB-135 com calibrador.

A aferição dos agentes físicos temperatura, ruído e iluminação foram feitas baseadas nos procedimentos técnicos e na normatização específicas contidas na NR15, NR-17 da CLT e na Norma-NBR 5.413 do INMETRO.

Os dados obtidos a partir da utilização dos diferentes instrumentos empregados na investigação foram sistematizados, tratados e apresentados através de tabelas, quadros e figuras.

\section{RESULTADOS E DISCUSSÃO}

A apresentação dos resultados encontra-se descrita segundo os três componentes da situação de trabalho considerados nesta investigação, ou seja, o homem, a atividade e o ambiente de trabalho. Inicialmente descreve-se informações sobre a unidade de internação estudada.

A unidade de Cardiologia destina-se ao atendimento de pacientes acometidos por afecções cardíacas, sendo composta por 38 leitos distribuídos em dois pavimentos sobrepostos e interligados através de uma rampa.

Do ponto de vista arquitetônico a sua composição é a seguinte.

- Primeiro pavimento: 3 enfermarias com banheiro;1 posto de enfermagem; 1 sala destinada a rouparia e arsenal de material; 1 expurgo; 1 depósito de material de transporte; 1 hall para prescrição médica; 1 banheiro para funcionários; 1 sala do serviço de nutrição e dietética.

- Segundo pavimento: 4 enfermarias com banheiro; 1 posto de enfermagem; 1 sala destinada a rouparia e arsenal de material; 1 expurgo; 1 hall para prescrição médica.

\section{- O Homem (trabalhador de enfermagem)}

A população de enfermagem na unidade é de 22 sujeitos sendo, 3 técnicos, 7 auxiliares, 8 atendentes de enfermagem e 4 enfermeiros, esses últimos apesar de serem lotados diretamente junto a chefia do serviço, executam supervisão e organização do trabalho de enfermagem na unidade.

\section{- Dados biográficos}

A construção da Tabela 1 permite uma configuração do perfil biográfico dos trabalhadores de enfermagem da unidade de internação estudada.

Tabela 1 - Número e percentual de trabalhadores de enfermagem da unidade de internação de cardiologia do hospital em estudo, segundo a categoria profissional e dados biográficos $(n=22)$

\begin{tabular}{l|cc|cccc|ccc}
\hline \multirow{2}{*}{$\begin{array}{c}\text { CATEGORIA } \\
\text { PROFISSIONAL }\end{array}$} & \multicolumn{2}{|c|}{ SEXO } & \multicolumn{4}{c|}{ ESTADO CIVIL } & \multicolumn{3}{c}{ IDADE } \\
\cline { 2 - 10 } & Fem. & masc. & solteiro & casado & viúvo & desquitado & $\mathbf{2 4 - | 3 0}$ & $\mathbf{3 0 - | 4 0}$ & $\mathbf{4 0 - | 4 8}$ \\
\hline Enfermeiro & 03 & 01 & 02 & 01 & 00 & 01 & 03 & 01 & 00 \\
Técnico de enf. & 03 & 00 & 01 & 01 & 00 & 01 & 03 & 00 & 00 \\
Auxiliar de enf. & 02 & 05 & 04 & 03 & 00 & 00 & 03 & 02 & 02 \\
Atendente de enf. & 06 & 02 & 00 & 05 & 02 & 01 & 02 & 04 & 02 \\
\hline TOTAL & 14 & 08 & 07 & 10 & 02 & 03 & 11 & 07 & 04 \\
& $63,6 \%$ & $36,4 \%$ & $31,8 \%$ & $45,5 \%$ & $9,1 \%$ & $13,6 \%$ & $50,0 \%$ & $31,8 \%$ & $18,2 \%$ \\
\hline
\end{tabular}

Em relação aos dados biográficos, $63,6 \%$ dos sujeitos são pertencentes ao sexo feminino e $36,4 \%$ ao masculino. $45,5 \%$ são casados, $31,8 \%$ solteiros, $9,1 \%$ viúvos e $13,6 \%$ desquitados. Possuem idade compreendida entre 24 e 48 anos sendo que $50,0 \%$ possuem idade na faixa etária de 24 a 30 anos, $31,8 \%$ entre 30 a 40 anos e $18,2 \%$ entre 40 a 48 anos.

Os resultados obtidos são coincidentes ao perfil da força de trabalho da enfermagem no Brasil descrito pelo Conselho Federal de Enfermagem e Associação Brasileira de Enfermagem, o qual é caracterizado como uma profissão eminentemente feminina apresentando escores variáveis dependendo a região do país entre $88,3 \%$ a $98,6 \%$ de mulheres; entre $40,4 \%$ e $56,6 \%$ são casados e com idade mais incidente na faixa etária de 20 a 40 anos (BRASIL, 1985).

O sexo é uma característica importante a ser observada quando é analisada a situação de trabalho 
porque existem diferenças significativas a serem consideradas. As mulheres, do ponto de vista fisiológico e psicológico, apresentam diversidades em relação aos homens. Possuem metabolismo e estatura física geralmente menor e sua força muscular representa em média dois terços daquela do homem. Quanto ao fator psicológico, enfrentam o estresse de maneira mais econômica do ponto de vista fisiológico, mas a um custo psicológico mais elevado, portanto tais diferenças precisam ser levadas em consideração (KALINO et al.,1988).

\section{- Dados antropométricos}

Através do calculo de percentis foi observado que $90 \%$ dos trabalhadores do sexo feminino possuem altura entre $1,54 \mathrm{~m}$ e $1,71 \mathrm{~m}$ e $90 \%$ dos trabalhadores do sexo masculino possuem altura entre $1,66 \mathrm{~m}$ e $1,75 \mathrm{~m}$ e em relação ao peso que $90 \%$ dos sujeitos do sexo feminino apresentam pesos entre $41,8 \mathrm{~kg}$ e $95 \mathrm{~kg}$ e $90 \%$ dos trabalhadores do sexo masculino apresentam pesos entre $46,8 \mathrm{~kg}$ e $88,5 \mathrm{~kg}$.

Diante da significativa rotatividade no serviço de enfermagem e da amplitude das variações das medidas antropométricas encontradas, consideramos viável a adoção do princípio de medidas médias para análise da adequação dos mobiliários existentes no ambiente de trabalho estudado. A altura em pé dos trabalhadores varia entre $1,54 \mathrm{~m}$ e $1,76 \mathrm{~m}$. A média das alturas dos trabalhadores do sexo feminino é $1,62 \mathrm{~m}$ (desvio padrão 0,0516), a média das alturas dos sujeitos do sexo masculino é $1,71 \mathrm{~m}$ (desvio padrão 0,03 ).

Em relação ao peso os trabalhadores possuem pesos entre $44,5 \mathrm{~kg}$ e $93 \mathrm{~kg}$. A média dos pesos para o sexo fem. é $68,4 \mathrm{~kg}$ (desvio padrão 16,1 ) e para o sexo masc. a média é de $67,6 \mathrm{~kg}$ (desvio padrão 12,6). Ao compararmos a altura e o peso dos trabalhadores aos valores de pesos desejáveis junto a tabela elaborada por Bray apud KRAUSE (1991), averiguamos que apenas $18,2 \%$ dos sujeitos apresentam pesos desejáveis.

A altura do cotovelo é relevante para o planejamento das bancadas de trabalho, pois essas devem ser construidas com base no tamanho do trabalhador e no tipo de trabalho a ser executado. A altura do cotovelo verificada na posição em pé, varia entre $92 \mathrm{~cm}$ a $107 \mathrm{~cm}$, os sujeitos pertencentes ao sexo fem. apresentam medidas menores quando comparadas às dos sujeitos pertencentes ao sexo masculino. A média observada nos trabalhadores do sexo fem. é de $96,14 \mathrm{~cm}$ e do masc. de $102,5 \mathrm{~cm}$.

Os estudos antropométricos têm ajudado a solucionar problemas entre grupos de trabalhadores buscando a adaptação entre eles e o seu trabalho. No entanto, na maioria das vezes, os responsáveis pela fabricação, aquisição ou concepção de mobiliários, equipamentos e postos de trabalho, ignoram que os trabalhadores possuem características antropométricas diferentes que merecem ser analisadas.

Diante da falta de atenção aos valores antropométricos em muitos hospitais, compete ao trabalhador adaptar essa situação não planejada e tal adaptação passa a ser entendida como esticar, curvar, entortar e contundir o corpo às exigências do trabalho (BULHÕES, 1994).

Consideramos que a altura das bancadas deva ser regulável, uma vez que as características individuais dos trabalhadores devem ser consideradas quando se almeja a adaptação do homem no trabalho.

\section{- Experiência profissional}

A unidade de Cardiologia possui 3 anos de funcionamento e devido a isso, o tempo máximo de serviço dos trabalhadores na unidade esta compreendido entre 2 e 3 anos. Quanto ao tempo de serviço na enfermagem observamos que $54,6 \%$ dos trabalhadores possuem entre 1 e 6 anos e que $40,9 \%$ dos sujeitos possuem menos de um ano de serviço na unidade, o que representa uma experiência não solidificada nesta unidade especializada.

\section{- Salários}

O salário recebido é variável segundo a categoria. Os enfermeiros relataram receber quantias líquidas entre 6 e 7 salários mínimos, os técnicos e os auxiliares entre 3 e 4 salários mínimos e os atendentes entre 1 e 2 salários mínimos. Para complementar o salário, 45,5\% trabalhadores possuem dois empregos.

\section{- Alguns elementos representativos da qualidade de vida}

Dos trabalhadores $54,5 \%$ possuem despesas com aluguéis ou parcelas de financiamento da casa própria. A grande maioria das moradias $(90,8 \%)$ possui saneamento básico, 18,2\% dos trabalhadores residem em cidade vizinhas, o que representa maior gasto de tempo e custos com o transporte.

A prática de atividades de lazer foram mencionadas por grande parte dos trabalhadores, no entanto, as atividades mais frequentemente realizadas são restritas a visitas a parentes e /ou amigos, assistir televisão e ouvir rádio. A necessidade de muitos trabalhadores possuirem dois empregos e de trabalharem em finais de semana e feriados, faz com que grande parte dos trabalhadores não consiga usufruir de momentos de lazer, os quais são considerados necessários para manutenção de uma vida saudável. 
Grande parte dos trabalhadores, $(72,7 \%)$, possuem horários irregulares de alimentação. 63,6\% referem alimentar-se, durante o turno de trabalho ingerindo salgadinhos, lanches e refrigerantes.

\section{- Impressões dos trabalhadores sobre suas condições de trabalho}

- Ambiente de trabalho: Em relação ao ambiente 45,5\% dos trabalhadores consideram-no confortável mas 54,5\% possuem opinião contrária devido à temperatura ambiental elevada. A iluminação é considerada adequada por $59,1 \%$ dos trabalhadores e inadequada por $40,9 \%$. Os motivos mencionados para esta inadequação são a falta de manutenção das lâmpadas, e inexistência de focos móveis. O nível de ruído e os espaços da unidade são considerados adequados por todo o pessoal de enfermagem.

- Segurança: Quanto à segurança 59,1\% dos trabalhadores consideram o ambiente seguro. Dentre os motivos alegados está o uso de equipamento de proteção individual. No entanto, $40,9 \%$ dos trabalhadores consideram o ambiente inseguro devido aos riscos existentes. A Tabela 2 apresenta os riscos apontados pelos trabalhadores.

Tabela 2 - Número de respostas emitidas em cada categoria de trabalhadores de enfermagem da unidade de internação de cardiologia do hospital em estudo, quanto aos riscos detectados

\begin{tabular}{|c|c|c|c|c|c|}
\hline \multirow{2}{*}{$\begin{array}{c}\text { Riscos } \\
\text { Detectados }\end{array}$} & \multicolumn{4}{|c|}{ Categoria Profissional } & \multirow[b]{2}{*}{ Total } \\
\hline & Enfermeiro & $\begin{array}{l}\text { Técnico de } \\
\text { enfermagem }\end{array}$ & $\begin{array}{c}\text { Auxiliar de } \\
\text { enfermagem }\end{array}$ & $\begin{array}{l}\text { Atendente de } \\
\text { enfermagem }\end{array}$ & \\
\hline $\begin{array}{l}\text { Falta comunicação sobre suspeitas e } \\
\text { diagnósticos de doenças } \\
\text { transmissiveis }\end{array}$ & 03 & 05 & 03 & 01 & 12 \\
\hline $\begin{array}{l}\text { Falta de material de proteção } \\
\text { individual }\end{array}$ & 02 & 02 & 01 & 00 & 05 \\
\hline $\begin{array}{l}\text { Inadequado acondicionamento do } \\
\text { material cortante no posto de } \\
\text { enfermagem }\end{array}$ & 00 & 01 & 03 & 00 & 04 \\
\hline $\begin{array}{l}\text { Manuseio de sangue e fluidos sem } \\
\text { luvas }\end{array}$ & 00 & 03 & 01 & 00 & 04 \\
\hline Falta sinalização "piso molhado" & 02 & 00 & 02 & 00 & 04 \\
\hline Piso é encerado, inclusive a rampa & 00 & 00 & 02 & 00 & 02 \\
\hline $\begin{array}{l}\text { Pano de chão é lavado onde são } \\
\text { lavados materiais sujos e } \\
\text { contaminados (expurgo) }\end{array}$ & 00 & 01 & 01 & 00 & 02 \\
\hline Não existe leito de isolamento & 02 & 01 & 00 & 00 & 02 \\
\hline $\begin{array}{l}\text { Improvisações devido à falta de } \\
\text { material }\end{array}$ & 00 & 00 & 01 & 01 & 02 \\
\hline
\end{tabular}

Constatamos que os trabalhadores conseguem detectar riscos biológicos, mas não associam fatores como a dificuldade de transportar pacientes, a manipulação de drogas, a grande variedade de atividades realizadas e a elevada temperatura ambiente como riscos eminentes do ambiente de trabalho.

Alguns trabalhadores identificam riscos no ambiente físico devido especificadamente à atuação do pessoal da limpeza, o qual é gerenciado pelo serviço de enfermagem. Os riscos apontados pelos trabalhadores indicam a necessidade de maior atenção, pelos enfermeiros, no que se refere à orientação e supervisão das atividades de limpeza na unidade.

- Motivos de insatisfação no trabalho: Os motivos apontados como fator de insatisfação no trabalho estão apresentados na Tabela 3. 


\begin{tabular}{|c|c|c|c|c|c|}
\hline \multirow{2}{*}{$\begin{array}{l}\text { Motivos de } \\
\text { Insatisfação }\end{array}$} & \multicolumn{4}{|c|}{ Categoria Profissional } & \multirow[b]{2}{*}{ Total } \\
\hline & Enfermeiro & $\begin{array}{c}\text { Técnico de } \\
\text { enfermagem }\end{array}$ & $\begin{array}{c}\text { Auxiliar de } \\
\text { enfermagem }\end{array}$ & $\begin{array}{l}\text { Atendente de } \\
\text { enfermagem }\end{array}$ & \\
\hline Baixos salários & 03 & 03 & 06 & 08 & 20 \\
\hline $\begin{array}{l}\text { A organização do trabalho não permite } \\
\text { que o enfermeiro preste cuidado direto } \\
\text { ao paciente }\end{array}$ & 03 & 00 & 00 & 00 & 03 \\
\hline $\begin{array}{l}\text { O trabalho em outras unidades para } \\
\text { "cobrir" faltas }\end{array}$ & 00 & 00 & 06 & 04 & 10 \\
\hline O reduzido número de funcionários & 02 & 00 & 03 & 02 & 07 \\
\hline $\begin{array}{l}\text { O relacionamento insatisfatório entre as } \\
\text { equipes médica e de enfermagem }\end{array}$ & 03 & 02 & 03 & 00 & 08 \\
\hline A falta de autonomia dos enfermeiros & 02 & 00 & 00 & 00 & 02 \\
\hline
\end{tabular}

Os principais motivos de insatisfação apontados são os baixos salários recebidos, o fato de serem escalados para trabalharem em outra unidade afim de cobrir faltas de colegas e o inadequado relacionamento entre as equipes de médica e de enfermagem, devido à não valorização pelos médicos do trabalho realizado pelo pessoal de enfermagem.

\section{- A atividade de trabalho}

\section{- As tarefas prescritas para o pessoal de enfermagem}

A partir do levantamento e análise documental, agrupamos as atividades prescritas nas categorias; administrativa, assistencial, de ensino e de pesquisa.

As tarefas prescritas pela instituição estão centradas em um serviço hierarquizado. O enfermeiro é responsável pelo desenvolvimento e manutenção da assistência de enfermagem e suas tarefas são predominantemente pertencentes à área administrativa, embora possua tarefas prescritas nas áreas assistencial, de ensino e pesquisa. As tarefas prescritas aos enfermeiros são condizentes às legalmente prescritas na Lei n 7.498/ 86 que dispõe sobre o exercício profissional da enfermagem no país (BRASIL,1986).

Uma característica evidenciada sobre o trabalho prescrito para o enfermeiro é que, assim como os demais enfermeiros brasileiros, segundo autores como ALMEIDA \& ROCHA (1986), durante a sua formação acadêmica, ele é preparado para a prestação de atividades predominantemente da área assistencial, mas quando é inserido no mercado de trabalho as instituições lhes atribuem tarefas, basicamente, de gerenciamento, delegando aos técnicos, auxiliares e atendentes de enfermagem a prestação de cuidados diretos.

Aos técnicos, auxiliares e atendentes de enfermagem, apesar de formação diferenciada, na instituição estudada são prescritas as mesmas tarefas, as quais estão voltadas predominantemente a área assistencial, pressupondo a execução de tarefas simples como cuidados higiênicos até tarefas de elevado grau de complexidade como o atendimento de pacientes em estado grave, urgências e administração de medicamentos.

Segundo a lei do exercício profissional de enfermagem no Brasil, o técnico de enfermagem é incumbido de executar tarefas auxiliares de nível médio técnico, basicamente cabendo-lhe assistir ao enfermeiro no planejamento, programação, orientação e supervisão das atividades de enfermagem e prestar cuidados diretos a pacientes, exceto os privativos do enfermeiro. Ao auxiliar de enfermagem tarefas de nível médio atribuídas à equipe de enfermagem cabendo-lhe preparar o paciente para consultas, exames, tratamento e procedimentos pósmorte, cuidados de enfermagem no pré-trans e pós operatório, cuidados de higiene, conforto, alimentação e segurança ao paciente, zelar pelo material e equipamentos e auxiliar o enfermeiro e o técnico de enfermagem na execução de programas de educação para saúde.

$\mathrm{O}$ atendente de enfermagem é autorizado legalmente a executar apenas atividades elementares de enfermagem.

As tarefas prescritas no Regimento do serviço de enfermagem da unidade de internação não são condizentes às prescritas na Lei do exercício profissional de enfermagem, uma vez que, não existe divisão de tarefas entre as categorias.

O trabalho prescrito, ou tarefa para GUÉRIN et al. (1991) refere-se ao modo de apreensão concreto do trabalho que corresponde a um conjunto de objetivos e prescrições apresentadas aos trabalhadores, mas definidas pela gerência para atender objetivos fixados pela instituição. A atividade, entretanto, é concernente ao 
trabalho efetivamente realizado pelo indivíduo, em um determinado período de tempo e no qual imprime sua marca pessoal.

Segundo dados da literatura nem sempre existe correspondência entre o trabalho real e o prescrito nas organizações, devido às características dos trabalhadores frente às regras de funcionamento da instituição, ao contexto de realização do trabalho e à saúde e eficiência dos trabalhadores.

A organização do trabalho real varia para cada trabalhador de acordo com as relações sociais, a elaboração da atividade, os modos operatórios reais e a dinâmica local da situação. Sendo assim, faz-se necessário a identificação das atividades efetivamente realizadas pelos trabalhadores de enfermagem na unidade a fim de se averiguar qual a relação existente entre o trabalho prescrito e o real.

\section{- Atividade efetivamente realizada}

O enfermeiro escala o trabalhador de enfermagem para prestação de cuidados à determinado número de pacientes (cerca de 7 pacientes nos turnos manhã e tarde e 11 pacientes no turno da noite), utilizando como critério o número de pacientes internados na unidade, o grau de dependência dos mesmos e o número de trabalhadores no turno. Este é um dos motivos que faz do absenteísmo do trabalhador de enfermagem um problema, pois quando o funcionário falta existe sobrecarga de serviço.

O enfermeiro assume o gerenciamento do serviço e da assistência, desempenhando basicamente atividades da área administrativa correspondendo a 83,6 \% do tempo de observação. Durante o turno da tarde permaneceu na unidade estudada apenas $35,3 \%$ da jornada de trabalho (212 minutos) e no turno da noite permaneceu na unidade 34,8\% (209 minutos) do tempo destinado a observação. Tais achados caracterizam um distanciamento do enfermeiro dos acontecimentos da unidade, o qual é considerado como motivo de insatisfação pelo próprio enfermeiro e pelos demais trabalhadores da unidade.

O trabalho prescrito aos enfermeiros, principalmente, se distancia-se do efetivamente realizado, uma vez que existem associações de vários elementos e procedimentos para execução de algumas atividades. Citamos como exemplo a comunicação, que na maioria das vezes é efetuada concomitantemente a outras atividades representando sobrecarga no trabalho executado.

Segundo MATOS (1994), a comunicação e o relacionamento que se estabelecem entre o enfermeiro e os demais membros da equipe de enfermagem e de saúde, têm influência direta no desenvolvimento das atividades, podendo favorecer ou dificultar o desenvolvimento do serviço. Ressalta que o enfermeiro assumir seu papel de gerente e coordenador da assistência de enfermagem ele deve estabelecer comunicação eficaz com seus diferentes interlocutores.

Outro aspecto a ser observado na execução das atividades, pelos enfermeiros, segundo MATOS (1994), é o deslocamento efetuado para a realização das atividades. Para assumir seu papel de gerente da assistencia, ele precisa buscar informações em locais diferentes. Com isso efetua muitos deslocamentos, que dependem das estratégias utilizadas para o desenvolvimento da atividade, da disposição arquitetônica da unidade e do tipo de cooperação que se estabelece entre os membros da equipe. Tais deslocamentos podem interferir, significamente, na carga cognitiva e física do trabalho realizado.

As atividades administrativas realizadas pelo enfermeiro têm grande representatividade em termos mentais, em razão das inúmeras informações usadas e da responsabilidade pelos acontecimentos em várias unidades nas quais estão envolvidos pacientes, trabalhadores, equipamentos e materiais e onde situações imprevistas podem ocorrer a todo instante, conduzindo a alterações inesperadas no plano de trabalho traçado.

Com vistas ao observado e ao relatado pelos enfermeiros identificamos algumas dificuldades enfrentadas, por esses profissionais, são ela; dificuldades relacionadas a fatores físicos (deslocamentos, força física na execução de atividades como transporte de pacientes e equipamentos; estrutura física inadequada da unidade), dificuldades relacionadas a fatores cognitivos (número elevado de informações acerca do paciente, diagnósticos, tratamentos, material, medicamento e equipamentos; constante necessidade de tomada de decisões; número elevado de comunicações; necessidade de conhecimento técnico-científico geral e específico voltado à Cardiologia); dificuldades devido a fatores organizacionais (o enfermeiro tem dificuldade na elaboração de escala mensal devido à impossibilidade de atendimento das solicitações de folgas e dificuldade na reorganização de escala diária devido à necessidade de remanejamento de trabalhadores), e ainda, dificuldades relacionadas a fatores psicossociais (falta de interação inter e intra equipes, necessidade de controle de sentimentos e emoções; distanciamento entre enfermeiros e pacientes).

Através da técnica de observação intervalar foram observadas as atividades efetivamente executadas pelos técnicos, auxiliares e atendentes de enfermagem durante os turnos de trabalho (manhã, tarde e noite). Através dos Gráficos 1 e 2 onde podemos observar, respectivamente, as atividades pertencentes à área administrativas e à área assistencial executada pelos técnicos, auxiliares e atendentes de enfermagem. 


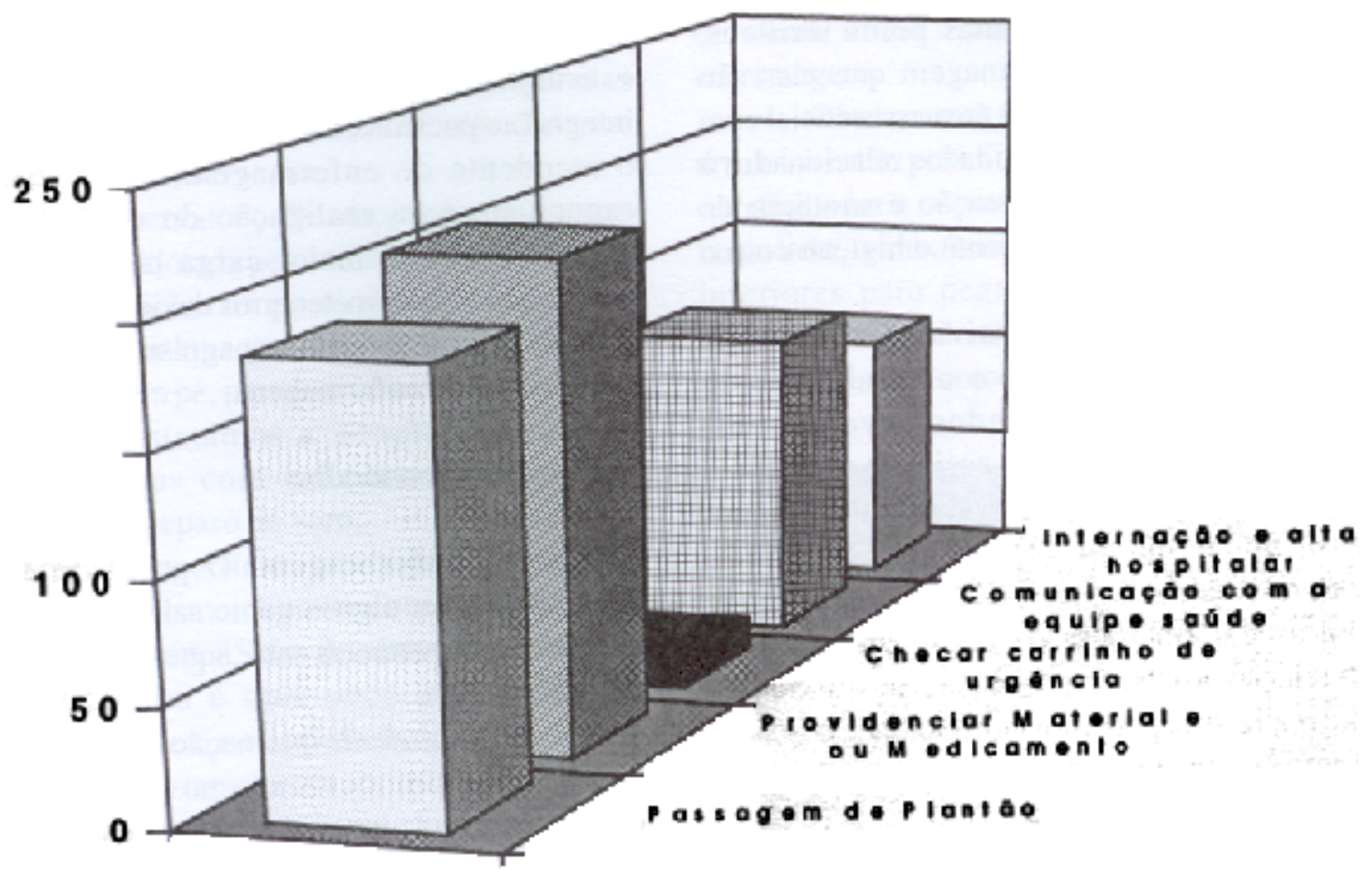

Gráfico 1 - Tempo (em minutos) dispensado pelos técnicos, auxiliares e atendentes de enfermagem na execução de atividades administrativas junto à unidade de internação de cardiologia do hospital em estudo

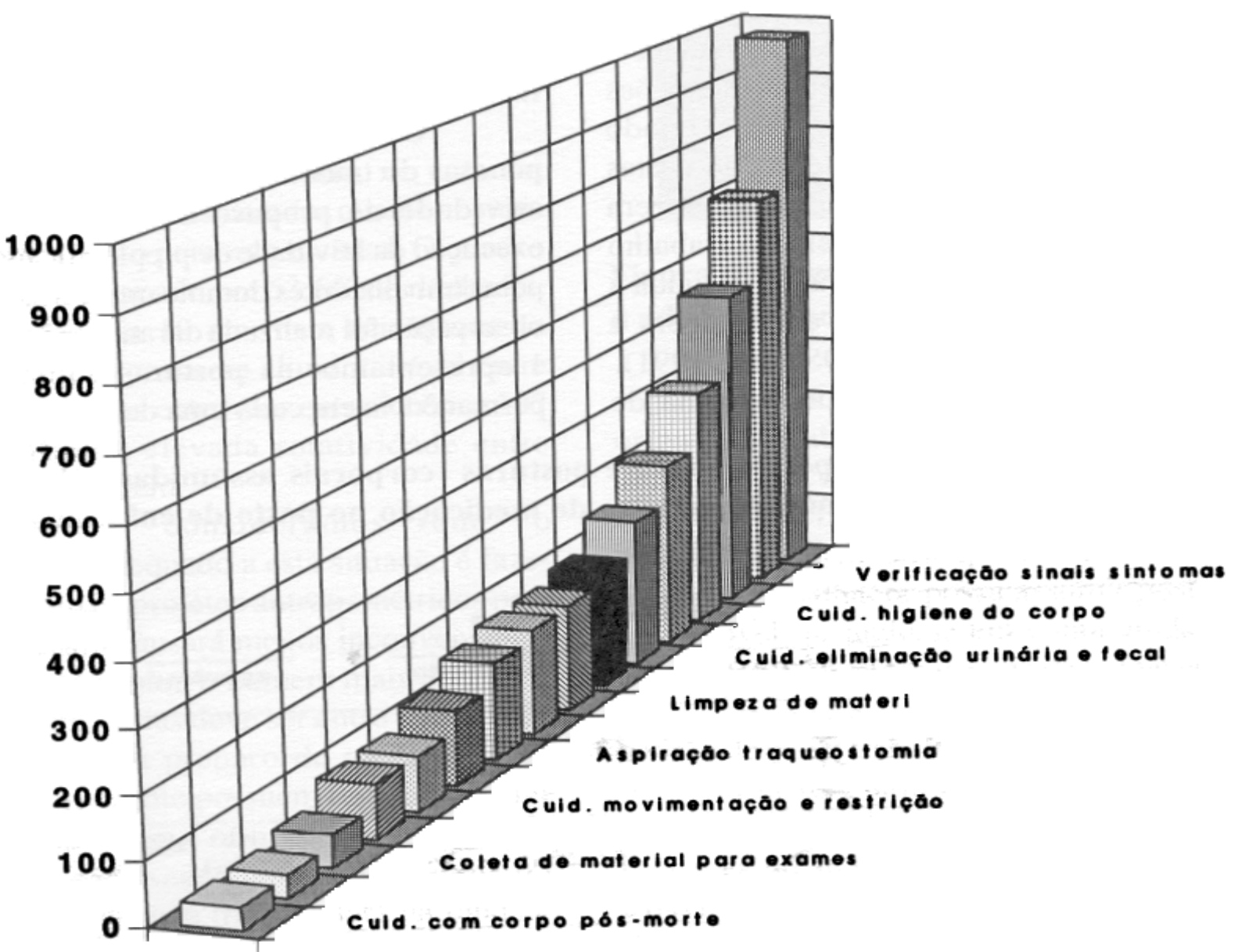

Gráfico 2 - Tempo (em minutos) dispensado pelos técnicos, auxiliares e atendentes de enfermagem na execução de atividades assistenciais junto à unidade de internação de cardiologia do hospital em estudo 
Podemos apreender, após a observação das atividades efetivamente executadas pelos técnicos, auxiliares e atendentes de enfermagem que elas são relacionadas mais frequentemente à área assistencial com predominância da execução dos cuidados relacionados à terapêutica medicamentosa, verificação e anotação de sinais e sintomas, higiene do ambiente e higiene com o corpo do paciente.

Durante a execução das atividades inúmeras informações devem ser retidas e o nível de atenção exigido é alto, pois o trabalhador deve avaliar, constantemente, o estado bio-psico-social do paciente, a fim de intervir e executar suas atividades de maneira adequada e no momento oporturno, sofrendo interferências do modo de organização do serviço, onde existem horários e normas a serem respeitadas.

Em relação aos aspectos técnicos das atividades efetivamente realizadas, podemos constatar que o pessoal de enfermagem executa um grande número de atividades durante a prestação da assistência.

A relação de trabalho estabelecida pelo pessoal de enfermagem se dá entre homens, portanto, precisa ser considerada de maneira especial, pois as exigências, principalmente mentais, estão muito presentes na situação de trabalho, devido às complexas relações que se estabelecem entre esses trabalhadores e os pacientes envoltos, freqüentemente, em situação de sofrimento.

As atividades executadas apresentam situações com múltiplas tarefas de natureza diversas, exigindo tomadas de decisões e organização e ordenação destas tarefas, em função dos fatos novos que se produzem sucessivamente, fatos estes que atribuem ao trabalho elevada carga mental. O preparo do profissional ajuda a reduzir a carga mental do trabalho de enfermagem e diminui a possibilidade de erro (SANTOS et al., 1991).

Os dados obtidos apontam que a forma de organização do trabalho, adotada na unidade, onde os técnicos, auxiliares e atendentes de enfermagem executam as mesmas atividades prestando cuidado integral ao paciente, mostra-se inadequada, uma vez que o atendente de enfermagem, um trabalhador não capacitado para realização do cuidado integral ao paciente, sofrerá maior carga mental e terá grande possibilidade de cometer erros devido à falta de formação, além de estar ocorrendo transgressão da lei do exercício profissional de enfermagem.

\section{- Os postos de trabalho}

- Posto de enfermagem: O posto de enfermagem, denominado por alguns como sala de serviço é um dos locais mais importantes entre aqueles usados pelo pessoal de enfermagem.

Na unidade de internação existem dois postos de enfermagem, um localizado no primeiro pavimento e outro no segundo pavimento. Possuem o mesmo espaço físico, quais sejam: $3,50 \mathrm{~m}$ de comprimento, $2,30 \mathrm{~m}$ de largura e pé direito de $3,0 \mathrm{~m}$.

As atividades executadas nos postos de enfermagem incluem o preparo de material e medicamentos a serem usados na assistência ao paciente, lavagens das mãos e a organização do posto que compreende a limpeza do mobiliário e ordenação do material e medicamentos.

Com o objetivo de investigar a adoção de posturas penosas do trabalhador de enfermagem na execução da atividade de preparo de medicação observamos a execução da atividade de preparo de medicação efetuadas pelos trabalhadores durante uma jornada de trabalho. Esta observação foi realizada durante 135 minutos. No Quadro 1 apresentamos as posturas adotadas e o tempo de permanência em cada uma delas.

Quadro 1 - Tempo (em minutos) de permanência e posturas corporais assumidas pelos trabalhadores de enfermagem para execução da atividade de preparo de medicação no posto de enfermagem da unidade de internação de Cardiologia do hospital estudado

\begin{tabular}{|c|c|c|c|c|c|}
\hline \multirow{2}{*}{$\begin{array}{l}\text { Pusicale } \\
\text { de } \\
\text { derne }\end{array}$} & \multicolumn{3}{|c|}{ Posicalo das permas } & \multirow[b]{2}{*}{ agachada } & \multirow[b]{2}{*}{ Total } \\
\hline & & eas pé-parade & andando & & \\
\hline reto & $\begin{array}{c}54 \min \\
(40,0 \%)\end{array}$ & & $\begin{array}{l}05 \min \\
(3,7 \%)\end{array}$ & - & $\begin{array}{c}59 \text { min } \\
(43,7 \%)\end{array}$ \\
\hline melinado & $\begin{array}{c}66 \text { min } \\
(48,9 \%)\end{array}$ & & $\begin{array}{l}03 \text { min } \\
(2,2 \%)\end{array}$ & $\begin{array}{l}02 \min \\
(1,5 \%)\end{array}$ & $\begin{array}{l}71 \mathrm{~min} \\
(52,6 \%)\end{array}$ \\
\hline toreido & $\begin{array}{l}03 \text { min } \\
(2,2 \%)\end{array}$ & & - & - & $\begin{array}{l}03 \min \\
(2,2 \%)\end{array}$ \\
\hline estirado & $\begin{array}{l}02 \text { min } \\
(1,5 \%)\end{array}$ & & $\overline{-}$ & - & $\begin{array}{l}02 \mathrm{~min} \\
(1,5 \%)\end{array}$ \\
\hline
\end{tabular}


Cabe mencionar que foram observadas todas as atividades de preparo de medicação efetuadas na jornada selecionada para observação, sendo que foram preparadas medicações para serem administradas através das vias oral, intra muscular e endovenosa.

Podemos observar no Quadro 1 que a postura mais freqüentemente adotada pelos trabalhadores, quando do preparo de medicações no posto de enfermagem é a em pé, parado, com a coluna vertebral inclinada $(48,9 \%)$, seguida pela postura em pé, parado com a coluna vertebral ereta $(40,0 \%)$. Constatamos a adoção de posturas consideradas penosas com estiramento da coluna vertebral, durante o preparo de soro.

A altura da superfícies usada para preparo de medição do posto do primeiro pavimento é de $98 \mathrm{~cm}$ e a do segundo pavimento é $85 \mathrm{~cm}$ de altura. A altura das bancadas de trabalho é uma peça importante no planejamento dos locais de trabalho que deve ser construída com base no tamanho do trabalhador e no tipo de trabalho a ser realizado.

A altura ideal da superfície de trabalho depende da altura dos cotovelos, com a pessoa em pé, e do tipo de trabalho que executa, ou seja, trabalho de precisão, trabalho leve e trabalho pesado. Em geral a superfície da bancada deve ficar 5 a $10 \mathrm{~cm}$ abaixo da altura dos cotovelos (IIDA,1990). O referido autor, recomenda que seria mais adequado dimensionar a altura da bancada pelo trabalhador mais alto e providenciar um estrado para os menores.

$\mathrm{Na}$ situação de trabalho estudada, no entanto, alguns aspectos merecem ser considerados quanto ao mais adequado dimensionamento para as bancadas. O quadro de pessoal da unidade é formado por $63,6 \%$ de mulheres, as mulheres são em média $10 \mathrm{~cm}$ mais baixas que os homens; os trabalhadores possuem altura variável entre $1,54 \mathrm{~m} \mathrm{e} 1,76 \mathrm{~m}$ e altura dos cotovelos entre $92 \mathrm{~cm}$ e 107 $\mathrm{cm}$ e o serviço enfrenta elevada rotatividade entre trabalhadores de enfermagem.

Sendo assim, consideramos que o dimensionamento mais adequado a esta situação é fazelo baseado no princípio de projetos antropométricos para o tipo médio, pois assim causará menos inconveniência do que se fosse projetado para o homem mais alto.

A altura das bancadas deve ser entre 89 e $94 \mathrm{~cm}$. As bancadas usadas para preparo de medicação do primeiro e segundo pavimento possuem respectivamente $98 \mathrm{~cm}$ e $85 \mathrm{~cm}$, as pias $88 \mathrm{~cm}$ e os carrinhos de urgência $84 \mathrm{~cm}$, portanto não estão adequados aos parâmetros antropométricos da população trabalhadora da unidade de internação, sendo que o ideal seria a adoção de bancadas com alturas ajustáveis.

A inadequação da altura das superfícies induz o trabalhador a curvar sua coluna vertebral ao executar suas atividades podendo ser considerado como fator predisponente ao aparecimento de lombalgias, problema de saúde muito freqüente entre os trabalhadores de enfermagem.

Observamos ainda que algumas gavetas dos armários estão posicionadas próximas ao piso induzindo o trabalhador a curvar sua coluna ao pegar material. Por outro lado, o trabalhador não utiliza a flexão dos membros inferiores para pegar o material nessas gavetas, há necessidade de alertá-los quando ao uso da adequação de movimentos com base nos princípios ergonômicos (Figura 1).

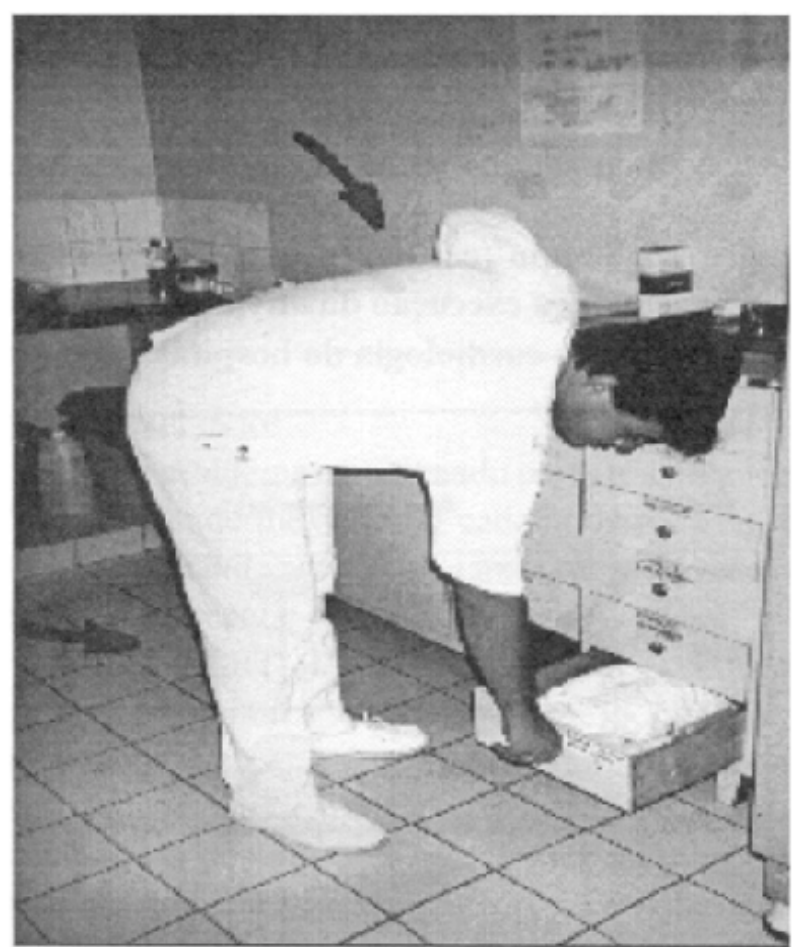

Figura 1 - As gavetas do armário são baixas induzindo a adoção de postura inadequada pelo trabalhador

Vários estudos vem sendo realizados a fim de orientar o trabalhador a posicionar-se corretamente durante a execução de suas atividades laborais, mas isto, segundo os ergonomistas, não é suficiente. Existe a necessidade de modificações também no trabalho, a fim de que o trabalhador possa assumir postura adequada e confortável, levando-se em conta ainda, a variação de movimentação e permanência de tempo em cada posição.

WISNER (1987) enfatiza que é preciso modificar a visão de que o trabalhador adota má postura porque ele não esta enxergando bem, ou não regula seu assento adequadamente, mas sim, que, na verdade, o trabalhador está se esforçando para responder às exigências da tarefa e das condições de inadequação na estrutura dimensional do posto de trabalho, mobiliários e iluminação, frente às suas características antropométricas.

A má postura é considerada quando existe falta de relacionamento entre as várias partes corporais, o que induz ao aumento das estruturas de suporte, levando ao 
desequilíbrio do corpo em suas bases de sustentação. A má postura leva à doença e está associada a problemas musculares e emocionais (KNOPLICH, 1989).

\section{- Enfermaria}

Na unidade de internação de Cardiologia existem em funcionamento sete enfermarias, sendo cinco compostas por seis leitos e duas por quatro leitos. As enfermarias possuem espaço físico entre $5,70 \mathrm{~m}$ X 4,70m, abrigando quatro leitos, e enfermarias de $6,80 \mathrm{~m}$ X $6,10 \mathrm{~m}$, que abrigam seis leitos.

Grande parte das atividades realizadas são efetuadas, nas enfermarias, pois é o local de permanência do paciente durante a internação. Dentre as atividades executadas, os trabalhadores de enfermagem consideram mais desgastante, fisicamente, as atividades de banho de chuveiro em pacientes que necessitam serem transportados através de cadeira de banho, arrumação de cama com paciente acamado, mudança de decúbito do paciente.

Diante das queixas dos trabalhadores observamos, durante uma jornada de trabalho, a execução da atividade de banho de chuveiro com auxílio e em uma outra jornada a execução de arrumação de cama com paciente acamado.

No Quadro 2, apresentamos as posturas adotadas pelos trabalhadores de enfermagem para realização da atividade de banho de chuveiro com auxílio e o tempo de permanência em cada postura.

Quadro 2 - Tempo (em minutos) de permanência e posturas corporais assumidas pelos trabalhadores de enfermagem para execução da atividade banho de chuveiro com auxílio executado na enfermaria da unidade de internação de cardiologia do hospital estudado

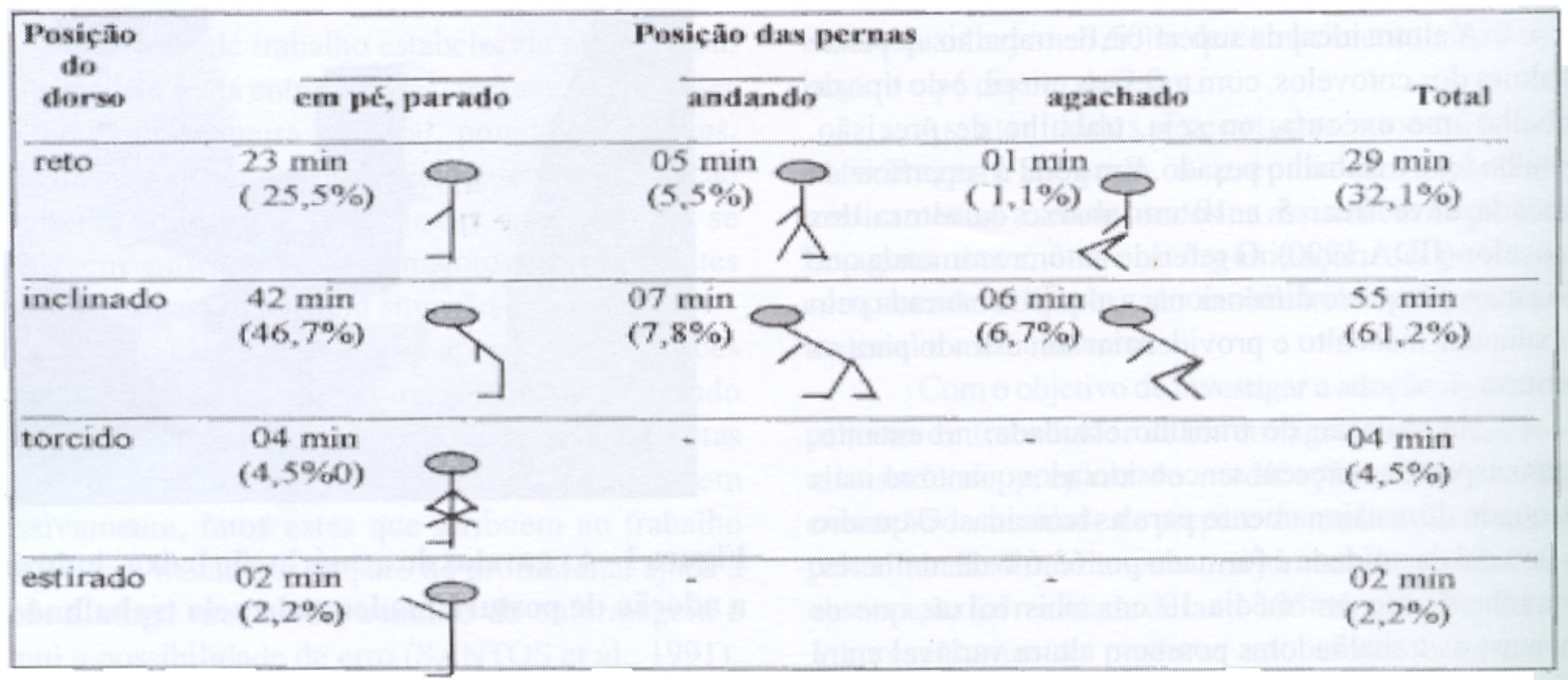

Na execução da atividade de banho de chuveiro com auxílio, realizada com o paciente impossibilitado de fazer sua higiene corporal sozinho e que geralmente não consegue se locomover sem ajuda, o pessoal de enfermagem transfere o paciente da cama que possui 70 $\mathrm{cm}$ de altura e $90 \mathrm{~cm}$ de largura, para uma cadeira de banho com altura do assento de $49 \mathrm{~cm}$.

MAURO (1980) ao estudar a transferência de pacientes de camas para cadeiras de rodas, constatou que a altura ideal para a cama deve ser entre $70 \mathrm{~cm}$ a $81 \mathrm{~cm}$ e para cadeira de rodas entre 55 a $60 \mathrm{~cm}$. Segundo este autor essas alturas além de proporcionar maior facilidade e menos desgaste físico ao pessoal, proporcionam maior segurança ao paciente.

Quando da realização do cuidado de higiene corporal, o trabalhador é induzido a inclinar sua coluna vertebral a nível torácico e lombar para realizar a atividade, e ainda quando da transferência do paciente para cadeira cuja altura do assento é inadequada.

Ao analisarmos as posturas assumidas pelo pessoal de enfermagem na execução da atividade de arrumação de cama com paciente acamado, constatamos que embora o tempo gasto para execução da referida atividade durante as jornadas de trabalho observadas não figura entre os mais freqüentes, a execução dessa atividade, segundo os trabalhadores, lhes é penosa.

Através do Quadro 3, apresentamos as posturas corporais assumidas pelos trabalhadores de enfermagem ao executarem a atividade de arrumação de cama com paciente acamado. Durante a jornada selecionada para realização da observação o pessoal de enfermagem foram observadas a arrumação de cinco camas, para as quais foram gastos 73 minutos. 
Quadro 3 - Tempo (em minutos) de permanência e posturas corporais assumidas pelos trabalhadores de enfermagem para execução da atividade arrumação de cama com paciente acamado executada junto a enfermaria da unidade de internação de cardiologia do hospital estudado

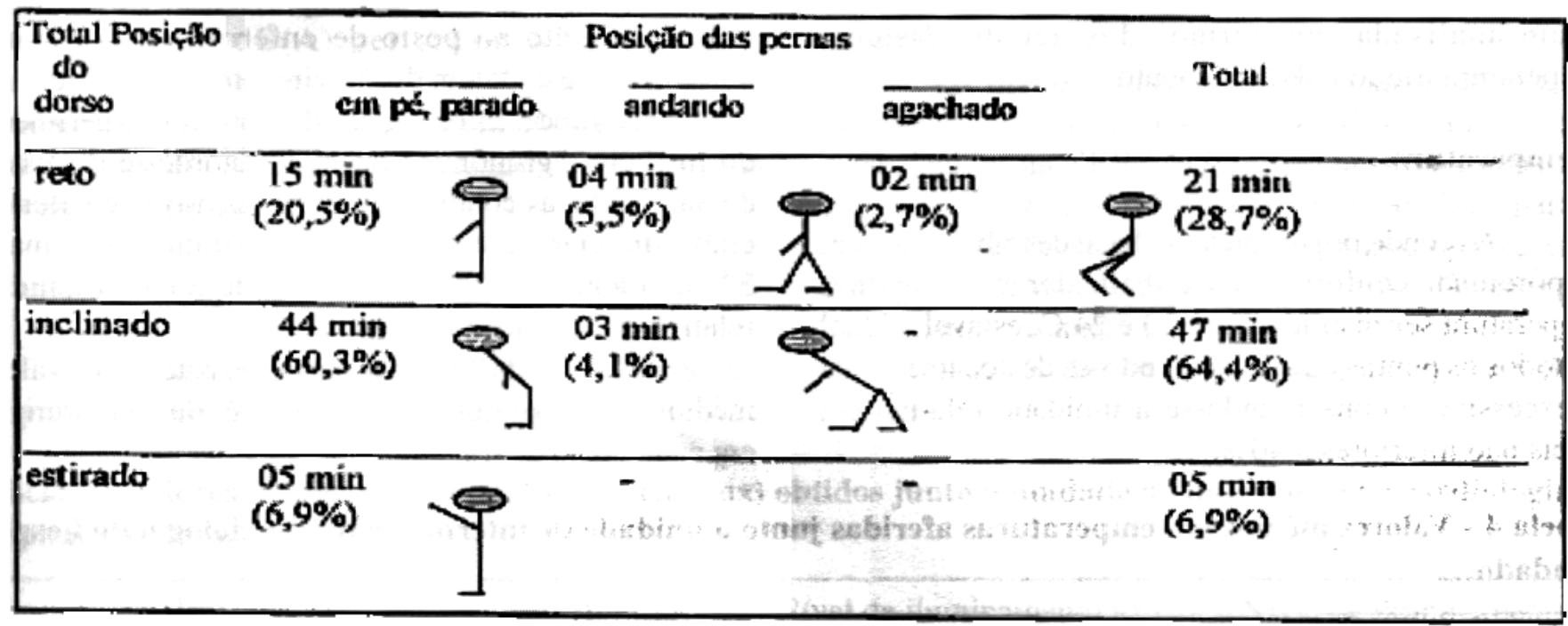

Durante a execução da atividade de arrumação de cama com o paciente acamado o pessoal de enfermagem assume a posição em pé parado $87,7 \%$ do tempo, 9,6\% andando e apenas $2,7 \%$ agachado. Quanto a posição do dorso assume $64,4 \%$ do tempo a coluna vertebral inclinada, $28,7 \%$ ereta e $6,9 \%$ estirada.

A adoção dessa atitude postural se deve em parte às características peculiares da atividade, à altura da cama considerada baixa em relação aos dados antropométricos do pessoal de enfermagem.

Há necessidade de empreendimento de esforço físico para mudar o paciente de um lado para outro da cama durante a troca de lençóis, mobilização de saco cheio de roupa suja para ser encaminhado a lavanderia (sendo assim necessário empreendimento de força) e existe também necessidade do trabalhador efetuar inúmeras flexões para colocação dos lençóis e abaixar e erguer a cama.

Outro fator que pode contribuir para o aumento de desgaste físico ao executar esta atividade é o fato de algumas camas posicionadas próximas as paredes laterais das enfermarias possuírem espaço inadequado o pessoal de enfermagem necessitando assim, move-los todas as vezes que for necessário executar atividades daquele lado da cama.

Segundo MONTEIRO-FILHO (1972) o pessoal de enfermagem necessita de no mínimo $55 \mathrm{~cm}$ de espaço para realização de movimentos ao executar suas atividades. O referido autor aponta ainda, a necessidade dos leitos estarem posicionados a 1,15 m de distância uns dos outros para manobras com macas, sendo $60 \mathrm{~cm}$ do espaço ocupado pela largura da maca e $55 \mathrm{~cm}$ ocupado pela presença de um trabalhador de enfermagem. Observamos que esses espaços na enfermaria analisada não são preservados.

Um problema mencionado pelos trabalhadores é na dificuldade de movimentar cadeira de roda entre os leitos, necessitando arrastar as camas todas as vezes que é necessário executar esta atividade.

LANGLET (1990) analisando a execução de todas as atividades executadas pelo pessoal de enfermagem refere que é adotada predominantemente a postura em pé para execução das atividades. Segundo esta autora, a postura inclinada, agachada ou com os braços elevados ultrapassam $10 \%$ do tempo de trabalho e aponta que o total de tempo em postura penosa varia entre $16 \%$ para as enfermeiras e $46 \%$ para as auxiliares de enfermagem, sendo que quanto maior o número de pacientes necessitando de que lhes faça higiene, troca de roupa de cama mais o trabalhador se curva.

LEE \& CHIOU (1995) estudando as posturas de trabalho do pessoal de enfermagem constataram que durante a execução das técnicas de enfermagem adotam $61,3 \%$ do tempo a postura em pé, dorso reto, andando com braços e ante braços flexionados, $43,0 \%$ do tempo a postura em pé,dorso reto, parado com braços e ante braços flexionados, $38,1 \%$ do tempo a postura em pé, parado, dorso inclinado e braços e ante braços flexionados, $21,4 \%$ em pé, parado, dorso reto e braços e ante braços flexionados. Constataram ainda no estudo realizado que $97,8 \%$ manipulam carga menor que 10 $\mathrm{kg} ; 1,7 \%$ cargas entre 10 e $50 \mathrm{~kg} \mathrm{e} 0,5 \%$ cargas maiores a $50 \mathrm{~kg}$.

\section{- O Ambiente}

Segundo os dispositivos legais contidos na Norma Regulamentadora-17 (BRASIL, 1994), as 
condições ambientais de trabalho devem estar adequadas às características psicofisiológicas dos trabalhadores e à natureza do trabalho executado.

Nesta investigação as condições ambientais foram analisadas em termos dos agentes físicos: temperatura, ruído e iluminamento.

\section{- Temperatura}

As condições térmicas do local de trabalho devem proporcionar conforto aos trabalhadores, devendo a temperatura ser mantida entre 20 e $24 \mathrm{C}$, estável e igual em todos os pontos da sala, evitando-se deslocamento de ar excessivo e conservando-se a umidade relativa em níveis não inferiores a $40 \%$.
As aferições foram efetuadas com a utilização de conjunto de termômetros de Bulbo úmido, seco e de globo através da determinação do Índice de Bulbo Úmido Termômetro de Globo (IBUTG). As aferições foram efetuadas junto ao posto de enfermagem e em uma enfermaria de cada um dos pavimentos da unidade.

Segundo informações da Estação Experimental do Instituto Agronômico da região nordeste do Estado de São Paulo, as condições climáticas do dia da aferição eram: dia claro e ensolarado, temperatura máxima de 32,9C, mínima de 20,9C e média de 26,9C, umidade relativa do ar igual a $68,7 \%$.

Através da Tabela 4, são apresentados os valores médios da temperatura obtidos através de duas aferições em cada posto de trabalho.

Tabela 4 - Valores médios de temperaturas aferidas junto a unidade de internação de cardiologia do hospital estudado

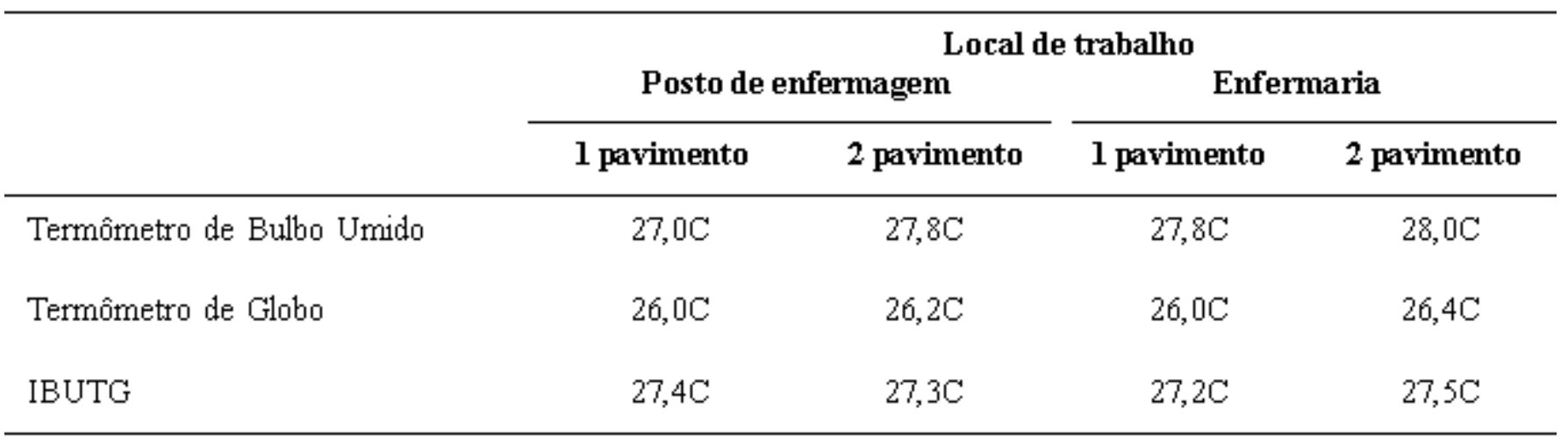

As características da situação de trabalho consideradas para efetuação dos cálculos foram: ambiente de trabalho interno sem carga solar, regime de trabalho contínuo e atividade moderada com base no quadro 3 da NR-15.

Os valores de IBUTG obtidos na unidade de internação caracterizam as condições térmicas do ambiente propiciadora de desconforto não só aos trabalhadores que ali atuam mas também aos pacientes.

Os valores elevados podem ser explicados pela deficiente circulação de ar na unidade, a qual é localizada no centro do hospital, circundada por outras unidades. Outros fatores que contribuem para o desconforto térmico são os vitrôs utilizados, alguns muito pequenos e fixos não permitindo a entrada de ar e as condições climáticas da região, que também influenciam, pois a temperatura é predominantemente elevada. O desconforto térmico acarreta prejuízos à saúde dos trabalhadores. $\mathrm{O}$ excesso de calor no ambiente ocasiona diminuição da capacidade de concentração e o aumento da fadiga.

\section{- Ruído}

O controle do ruído ambiental é considerado por FANTAZZINNI et al. (1985) como um eficiente instrumento da estratégia de diminuição de riscos ambientais, pois é sabido que níveis elevados de ruído pode causar danos a saúde.

Segundo a NR-17 para as atividades que exijam solicitação intelectual e ou atenção, o nível de ruído não deverá exceder a $60 \mathrm{~dB}(\mathrm{~A})$.

A norma NBR 10152 da Associação Brasileira de Normas Técnicas - ABNT, recomenda para existência de conforto acústico para projetos de edificações em hospitais níveis de ruído estabelecidos entre 35 a 45 $\mathrm{dB}(\mathrm{A})$.

Foram aferidos os níveis de ruído na unidade através de três medições junto ao posto de enfermagem e uma enfermaria de cada um dos pavimentos da unidade de internação. Após efetuação de calibração do decibelímetro de capacidade de $50 \mathrm{~dB}$ a $120 \mathrm{~dB}$. Os valores médios encontrados através das medições foram de $50 \mathrm{~dB}(\mathrm{~A})$ nos postos de enfermagem do primeiro e segundo pavimentos, de $55 \mathrm{~dB}(\mathrm{~A})$ na enfermaria do primeiro pavimento e $60 \mathrm{~dB}(\mathrm{~A})$ no segundo.

Segundo BLANPAIN \& ESTRYN-BEHAR (1990) para o conforto dos pacientes, é recomendado no ambiente hospitalar nível de ruído igual a $35 \mathrm{~dB}(\mathrm{~A})$ a noite e $40 \mathrm{~dB}(\mathrm{~A})$ durante o dia. Esses níveis de ruído 
ambiental permitem conversação em tom de voz normal, entre 40 e $45 \mathrm{~dB}(\mathrm{~A})$, pois níveis sonoros mais elevados obrigam as pessoas a falarem em voz mais alta, entre 55 e $70 \mathrm{~dB}(\mathrm{~A})$. Os autores apontam ainda que níveis de ruído superiores a $55 \mathrm{~dB}(\mathrm{~A})$ perturbam a performance intelectual do homem dificultanto a realização de atividades complexas e como já vimos anteriormente várias atividades executadas pelo pessoal de enfermagem são consideradas complexas.

\section{- Iluminação}

A iluminação adequada no local de trabalho proporciona um ambiente agradável e diminue as possibilidades de acidentes (GIAMPAOLI, 1985).

Segundo dados da NR-17 (BRASIL, 1994) em todos os locais de trabalho deve haver iluminação adequada, natural ou artificial, apropriada à natureza da atividade.

Os níveis mínimos de iluminamento* a serem observados nos locais de trabalho são aqueles estabelecidos na NBR 5413, norma brasileira registrada no INMETRO. O iluminamento recomendado para as dependências de modo geral de hospitais é variável entre 200 a 300 Lux, não existindo portanto especificações para cada posto de trabalho.

Através da Tabela 5, apresentamos os valores aferidos.

Tabela 5 - Valores médios de iluminamento (em Lux) obtidos junto a unidade de internação de cardiologia do hospital estudado

\begin{tabular}{lccc}
\hline \multicolumn{1}{c}{ Local de Trabalho } & Horário & $\begin{array}{c}\text { Nivel de iluminamento nas } \\
\text { condições de trabalho (LUX) }\end{array}$ & $\begin{array}{c}\text { Nivel de iluminamento } \\
\text { (LUX) }\end{array}$ \\
\cline { 3 - 4 } & & & Sem luz artificial \\
\hline $\begin{array}{l}\text { Bancada do posto de enfermagem } \\
\text { (primeiro pavimento) }\end{array}$ & $08: 00$ & 186 & 103 \\
& $20: 00$ & 150 & 00 \\
Bancada do posto de enfermagem & $09: 20$ & 274 & 118 \\
(Segundo pavimento) & $21: 25$ & 145 & 01 \\
& & & 12 \\
Enfermaria & $08: 50$ & 190 & 02 \\
(primeiro pavimento) & $20: 50$ & 167 & 10 \\
& $10: 15$ & 192 & 02 \\
Enfermaria & $22: 10$ & 149 & \\
(Segundo pavimento) & & & 12 \\
\hline
\end{tabular}

Passamos a descrever as características dos postos de trabalho.

- Posto de enfermagem: Iluminação artificial produzida por uma luminária contendo duas lâmpadas frias de 40 watts, iluminação natural devido a incidência de raios solares adentrados através de dois pequenos vitrôs.

- Enfermarias: Iluminação artificial por quatro luminárias contendo cada uma duas lâmpadas frias de 40 watts, iluminação natural através da incidência de raios luminosos por entre dois vitrôs de $250 \mathrm{~cm} \mathrm{X} 82 \mathrm{~cm}$.

Observamos que nas enfermarias todas as luzes são acionadas por um único interruptor o que durante o noite prejudica o sono dos pacientes e é fator de desconforto para o trabalhador, pois necessita acender as luzes para realização de suas atividades mesmo que com um único paciente em uma enfermaria de seis leitos.

Alguns leitos ficam distantes do foco de luz e nesses o trabalhador enfrenta dificuldades na realização da atividade de administração por via intravenosa, leitura de escalas de termômetro e esfigmomanômetro entre outras. A iluminação na enfermarias, portanto não é uniformemente distribuída.

Segundo BLANPAIN \& ESTRYN-BEHAR (1990) nas enfermarias devido as atividades ali realizadas torna-se indispensável uma iluminação adequada a qual deve ser de 300 Lux, a fim de que possam ser observados detalhes como por exemplo cianose. Os dados aferidos na enfermarias estudadas são inferiores a 200 Lux.

Nos postos de enfermagem onde o preparo de

\footnotetext{
* Iluminamento é a grandeza que mede a intensidade luminosa sobre uma superfície em Lux.

Lux é a unidade de medida de iluminamento onde o iluminamento de uma superfície de área igual a $1 \mathrm{~m}$ quadrado, recebendo a direção normal um fluxo luminoso de 1 lumém
} 
medicações e leitura de prescrições possuem maior exigência visual os valores de iluminamento encontrados necessitam de adequação pois, segundo BLANPAIN \& ESTRYN-BEHAR (1990) o trabalho realizado no posto de enfermagem como exemplo o preparo de medicamentos que necessita de leitura de ampolas, graduação de seringas, deve possuir iluminação média de 500 Lux.

Diante do exposto consideramos que algumas medidas devam ser tomadas a fim de adequar o ambiente de trabalho na unidade estudada. A temperatura ambiente é elevada e desconfortante, no verão, para os trabalhadores e pacientes, este problema pode ser amenizado ou eliminado através da instalação de ventiladores e melhor posicionamento dos vitrôs (deixando-os abertos).

Em relação ao ruído, embora constatado níveis ligeiramente elevados para a situação hospitalar, esses níveis não estão ocasionando desconforto aos trabalhadores de enfermagem. A iluminação na unidade estudada apresenta problemas, principalmente, junto aos postos de enfermagem, onde os níveis de iluminamento são inferiores a 200 Lux, segundo dados da literatura o iluminamento adequado para esses locais é de 500 Lux. Nas enfermarias há necessidade de colocação de interruptores que acionem separadamente as lâmpadas e focos móveis para utilização em atividades que exijam maior nível iluminamento.

\section{CONCLUSÕES}

A partir da identificação do trabalhador de enfermagem, das atividades que executam e de aspectos do ambiente físico e da interpelação desses elementos, foi possível conhecer e caracterizar situação de trabalho do pessoal de enfermagem da unidade de internação.

\section{- O trabalhador}

O trabalhador de enfermagem da unidade estudada é em grande parte pertencente ao sexo feminino, com idade mais incidente entre 24 a 30 anos. Apresenta escolaridade variável, sendo que, $27 \%$ dos trabalhadores possuem formação de primeiro grau. Apresentam dados antropométricos variáveis sendo a altura entre $1,54 \mathrm{~m}$ e $1,76 \mathrm{~m}$ e peso entre $44,5 \mathrm{~kg}$ e $93 \mathrm{~kg}$.

A formação profissional constitui-se um problema, uma vez que, a distribuição das atividades efetivamente realizadas não obedece às exigências legalmente estabelecidas. A divisão de tarefas utilizada interfere na prestação da assistência e causa desgaste mental nos trabalhadores, aumentando a probabilidade de ocorrência de erros e acidentes.
A variação do peso, da altura e do sexo dos trabalhadores demostram a necessidade da utilização de equipamentos e mobiliários de alturas ajustáveis, a fim de evitar esforços desnecessários e problemas osteomusculares.

A opinião do trabalhador frente sua situação de trabalho é um indicativo da conscientização que o trabalhador tem frente as condições de trabalho que lhe é oferecida.

O ambiente de trabalho é adequado para a metade dos trabalhadores, sendo que, todos consideram o nível de ruído e os espaços da unidade adequados. Cerca da metade dos trabalhadores consideram a iluminação adequada e temperatura ambiente elevada. Em relação a segurança do trabalho, cerca da metade dos trabalhadores percebem a existência de riscos no ambiente de trabalho, sendo identificados basicamente os riscos biológicos.

São apontados como motivos de insatisfação no trabalho; baixos salários, a necessidade de cobrir falta de outros funcionários em unidades diferente daquela que o funcionário atua rotineiramente e as dificuldades de relacionamento e comunicação intra e inter equipes médica e de enfermagem.

\section{- Atividade de trabalho}

Os enfermeiros executam predominantemente atividades pertencentes à área administrativa. De acordo com a organização de trabalho na unidade os técnicos, auxiliares e atendentes de enfermagem executam as mesmas atividades, as quais são predominantemente pertencentes a área assistencial, sendo empreendido a maior parte do tempo da jornada de trabalho na execução de: cuidados com a terapêutica medicamentosa, verificação e anotação de sinais e sintomas e cuidados de higiene do ambiente e do corpo do paciente.

Os postos de trabalho onde as atividades são executadas apresentam inadequação na altura dos mobiliários induzindo o trabalhador a inclinação do dorso e propiciando-lhe desconforto.

\section{- Ambiente}

Foi constatado que a temperatura é elevada nos postos de trabalho, indicando inadequação das condições térmicas do ambiente, as quais propiciam desconforto aos trabalhadores e pacientes. Quanto ao iluminamento constatamos que o iluminamento na unidade é efetuado basicamente por iluminação artificial, haja visto a pequena incidência de luz natural junto aos postos de trabalho e que os níveis de iluminamento são inferiores à 200 Lux, os quais são considerados inadequados para o tipo de atividades executadas no ambiente hospitalar.

Os níveis de ruído apresentam-se ligeiramente 
elevados, os quais obrigam as pessoas a aumentarem o tom de voz, e este como se sabe pode perturbar a performance mental quando da execução de atividades complexas.

A opinião dos trabalhadores sobre a situação de trabalho e a realidade avaliada pelos padrões ergonômicos nos permitiu a identificação de problemas para os quais sugerimos proposta de intervenção objetivando a melhoria das condições de trabalho e a redução do absenteismo-doença, pois consideramos que as faltas no trabalho, apesar de estarem diagnosticadas como relativas à problemas de saúde, ocorrem devido à fatores relacionados a forma de organização do trabalho, inadequada divisão de tarefas, inadequação de equipamentos, materiais e mobiliários, inadequação das estratégias de comunicação usadas, baixos salários levando a jornada dupla trabalho, fatores esses que caracterizam a má qualidade de vida no trabalho experenciadas por esses trabalhadores.

Apresentamos nossa proposta de intervenção, elaborada com vistas aplicação das modalidades de intervenção ergonômica quais sejam: de concepção que esta relacionada ao planejamento de equipamentos, instrumentos e ambientes de trabalho antes de sua construção, de correção que procura melhorar as condições já existentes e de conscientização que aponta ao trabalhador os fatores de riscos do ambiente de trabalho e como ele deve atuar nessas ocasiões.

Concepção: O trabalhador de enfermagem deve participar efetivamente no planejamento das unidades de internação, quer seja, no dimensionamento de espaços, como de mobiliários. Os dados antropométricos do pessoal de enfermagem, devem ser considerados com vistas a garantir condições favoráveis a execução das atividades de enfermagem em todos os postos de trabalho.

Correção: Na tentativa de adequar as condições de trabalho, já existentes, na unidade de internação de Cardiologia às características da população trabalhadora faz-se necessário:

- viabilizar aumento salarial, uma vez que este é um dos motivos de maior insatisfação do trabalhador, o qual tem repercussão em sua qualidade de vida, marcada por dificuldades de moradia, alimentação, transporte e lazer; - utilizar estratégias para melhorar o relacionamento e a comunicação entre as equipes médicas e de enfermagem; - oferecer freqüentemente cursos de reciclagem para melhor capacitar os trabalhadores da unidade para a prestação de assistência a pacientes portadores de doenças cardíacas;

- faz-se necessário ainda, que a equipe médica estabeleça um canal efetivo de comunicação com o pessoal de enfermagem sobre suspeitas diagnósticas de afecções infecto contagiosas, para que a enfermagem utilize as precauções necessárias para sua proteção e dos pacientes;
- orientar os trabalhadores quanto aos fatores de riscos do ambiente hospitalar, afim de que possam utilizar medidas preventivas relativas as doenças ocupacionais e acidentes de trabalho;

- rever e reformular as atividades prescritas ao pessoal de enfermagem junto ao Regimento técnico da unidade de internação e reorganizar a divisão de tarefas na unidade assegurando aos atendentes de enfermagem a execução de atividades de menor grau de complexidade;

- organizar de forma adequada o provimento de material; - utilizar camas e macas e cadeiras de banho de altura regulável visando o menor desgaste físico do pessoal de enfermagem e maior conforto ao paciente;

- adquirir elevador de paciente para facilitar o transporte de pacientes;

- executar o transporte de paciente através da rampa utilizando dois trabalhadores;

- adequar as alturas das bancadas de trabalho (entre 89 e $94 \mathrm{~cm})$

- reorganizar o armazenamento do material de uso mais freqüente nos armários evitando as gavetas de altura mais baixa e as prateleiras mais altas;

- utilizar apoio para os pés quando da execução de atividades em bancadas de alturas baixas;

- orientar e treinar o pessoal de enfermagem quanto a utilização de princípios de mecânica corporal e de Ergonomia quando da execução de suas atividades laborais;

- adquirir cadeiras ergonomicamente planejadas;

- instalar ventiladores, ampliar os vitrôs e fazer com que suas básculas permaneçam abertas;

- aumentar o iluminamento da unidade para no mínimo 200 Lux e particularmente nos postos de enfermagem o iluminamento onde deve ser de 500 Lux, colocar outros interruptores nas enfermarias, luzes na cabeceira de cada leito e foco móvel para ser usado quando a atividade exigir.

Conscientização: É necessário conscientizar o trabalhador de enfermagem sobre as formas seguras de trabalho, para tal sugerimos o oferecimento de treinamento específico a especialidade de Cardiologia quando da admissão e oferecimento contínuo de cursos de reciclagem referentes ao atendimento de parada cardiorespiratória, urgências, procedimentos técnicos de enfermagem, assepsia, relacionamento interpessoal, precauções padrão (universais) e princípios relativos a mecânica corporal e Ergonomia.

O trabalhador deve reconhecer os agentes físicos, químicos, biológicos, psicossociais e ergonômicos provenientes do ambiente de trabalho hospitalar e saber como proceder diante de cada agente causador de risco a fim de preservar sua saúde. 

CARDIOLOGY

Aiming at finding out the ergonomics conditions of the nursing personnel in a hospital admission unit, the authors utilized as a methodological presuposition the search for a global experienced work situation through the analysis of some elements as: the man (nursing worker); the work activity (prescribed duty, real activities and work position) and the environment (temperature, noise and illumination). The authors selected the Cardiology admission unit for the site of their research. The results verified that the nursing workers the mentioned unit face problems related to salaries, work installations, relationship, work organization, levels of formation and the activities executed. The authors suggested some recommendations.

UNITERMS: work, nursing, ergonomics

\section{CONDICIONES ERGONÓMICAS DEL TRABAJO DE LA EQUIPE DE ENFERMERÍA EN UNIDAD DE INTERNACIÓN DE CARDIOLOGÍA}

Con el objetivo de analizar las condiciones ergonómicas de la situación de trabajo del personal de enfermería en una unidad de internación hospitalar, utilizamos como presupuesto metodológico la globalidad de la situación experenciada a trasis de la análises de sus elementos, los cudes serion: el hombre (trabajador de enfermería), la actividad de trabajo (tareas prescriptas, actividades redas y puestos de trabajo) y el ambiente (temperatura, ruido e iluminación). Buscando la demanda para la investigación identificamos la unidad de Cardiología como lugar para la realización de la pesquisa. Los resultados senalaron que el trabajador enfrenta problemas relacionados a la inadequación de sueldos, de los puestos de trabajo, en el relacionamento, en la organización de trabajo, en el nivel de formación y en las actividades ejecutadas. Frente a la situación se presentarán las recomendaciones.

TÉRMINOS CLAVES: trabajo, enfermería, ergonomía

\section{REFERÊNCIAS BIBLIOGRÁFICAS}

01. ABRAHÃO, J. Ergonomia: modelo, métodos e técnicas. Florianópolis: ABERGO, 1993.

02. ALMEIDA, M.C.P.; ROCHA, J.S.Y. O saber da enfermagem e sua dimensão prática. São Paulo: Cortez, 1986.

03. BLANPAIN, G.; ESTRYN-BEHAR, M. Mensures d'ambiance physique dans dix services hospitaliers. Performances, London, n. 45, p. 18-33, jan./fév. 1990.

04. BRASIL. Conselho Federal de Enfermagem. O exercício de enfermagem nas nas instituições de saúde no Brasil: 1982/1983. Rio de Janeiro: COFEn/ABEn, 1985. p.36. v. 1.

05. BRASIL. Lei n. 7.498, de 25 de junho de 1986. Dispõe sobre a regulamentação do exercício da enfermagem e dá outras providências. Diário Oficial da União, Brasília, 26 jun. 1986. Seção 1, p. 273-5.

06. BRASIL. Ministério do trabalho. Gabinete do Ministro. Portaria n. 3.214, de 8 de junho de 1978: Normas Regulamentadoras. In: SEGURANÇA e medicina do trabalho. Atlas, 1994. p.19-274.

07. BULHÕES, I. Riscos do trabalho de enfermagem. Rio de Janeiro: Folha Carioca, 1994. 221 p.

08. COUTO, H.A. Temas de saúde ocupacional. Belo Horizonte: ERGO, 1987. 427 p.
09. FANTAZZINNI, M.L. et al. Norma para avaliação da exposição ocupacional ao ruido. Rev. Bras.Saúde Ocup., São Paulo, v. 13, n. 50, p. 92-96, 1985.

10. GIAMPAOLI, E. Temperaturas estremas. In: ASTETE, M.W.et al. Riscos físicos. São Paulo: Fundacentro, 1985. p.33-99.

11. GUÉRIN, F. et al. Comprendre le travail pour le transformer la pratique de l'ergonomie. Paris: ANACT, 1991.

12. IIDA, I. Ergonomia: projeto e produção. São Paulo: Edgard Blucher, 1990. 465 p.

13. KALINO, R. et al. Compiladores: los factores psicosociales en el trabajo y su relacion con la salud. Genebra: OMS, 1988. p. 27-144.

14. KNOPLICH , J. Endirite as costas. São Paulo: IBRASA, 1989.

15. KRAUSE, M.V. Alimentos, nutrição e dietoterapia: um livro-texto do cuidado nutricional. 2. ed. São Paulo: Roca, 1991.

16. LANGLET, M. Ergonomie et soins infirmiers: la santé des soignants. Paris: Editions Lamarre, 1990. p.11.

17. LEE, Y.H.; CHIOU W.K. Ergonomic analysis of working posture in nursing personnel: example of modified Ovako Working Analysis System Application. Res. Nurs. Health, New York, v. 18, n. 1, p. 67-75, 1995. 
18. MATOS, D.G. de. O trabalho do enfermeiro do centro cirúrgico: um estudo sob a ótica da ergonomia. Brasilia,1994. 160 p. Dissertação (Mestrado) - Instituto de Psicologia, Universidade de Brasilia.

19. MAURO, E. A. Engenharia do comportamento: uma contribuição à análise de dois equipamentos de uso hospitalar e a definição de ambiente terapêutico. São Paulo,1980. 166 p. Tese (Doutorado) - Instituto de Psicologia, Universidade de São Paulo.

20. MONTEIRO-FILHO, A. J. Estudo do aspecto físico da unidade de internação em hospital geral. São Paulo, 1972. 88 p. Tese (Doutorado) Faculdade de Saúde Pública, Universidade de São Paulo.
21. SANTOS, N.; JARUFE, M.S.; AMORIM, J.L. Saúde e trabalho dos operários da saúde: um diagnóstico da ergonomia. In: SEMINÁRIO BRASILEIRO DE ERGONOMIA, 5. , 1991, São Paulo. Anais. São Paulo: Oboré, 1991. p. 199-200.

22. SLUCHAK, T.J. Ergonomics: origins, focus and implementation considerations. A.A.O.H.N. J., v. 40, n. 3, p. 105-112, Mar. 1992.

23. WISNER, A. Por dentro do trabalho.

Ergonomia: método e técnica. São Paulo: FTD/ OBORÉ., 1987. 